\title{
Fetal weight estimation by automated three-dimensional limb volume model in late third trimester compared to two- dimensional model: a cross-sectional prospective observational study
}

\author{
Xining Wu, Zihan Niu, Zhonghui Xu, Yuxin Jiang, Yixiu Zhang, Hua Meng ${ }^{*+}$ and Yunshu Ouyang ${ }^{*+}$
}

\begin{abstract}
Background: Accurate estimation of fetal weight is important for prenatal care and for detection of fetal growth abnormalities. Prediction of fetal weight entails the indirect measurement of fetal biometry by ultrasound that is then introduced into formulae to calculate the estimated fetal weight. The aim of our study was to evaluate the accuracy of fetal weight estimation of Chinese fetuses in the third trimester using an automated three-dimensional (3D) fractional limb volume model, and to compare this model with the traditional two-dimensional (2D) model.

Methods: Prospective 2D and 3D ultrasonography were performed among women with singleton pregnancies 7 days before delivery to obtain 2D data, including fetal biparietal diameter, abdominal circumference and femur length, as well as 3D data, including the fractional arm volume (AVol) and fractional thigh volume (TVol). The fetal weight was estimated using the 2D model and the 3D fractional limb volume model respectively. Percentage error was defined as (estimated fetal weight - actual birth weight) divided by actual birth weight and multiplied by 100 . Systematic errors (accuracy) were evaluated as the mean percentage error (MPE). Random errors (precision) were calculated as \pm 1 SD of percentage error. The intraclass correlation coefficient (ICC) was used to analyze the interobserver reliability of the 3D ultrasound measurements of fractional limb volume.

Results: Ultrasound examination was performed on 56 fetuses at $39.6 \pm 1.4$ weeks' gestation. The average birth weight of the newborns was $3393 \pm 530 \mathrm{~g}$. The average fetal weight estimated by the 2D model was $3478 \pm 467 \mathrm{~g}$, and the MPE was 3.2 \pm 8.9. The average fetal weights estimated by AVol and TVol of the 3D model were $3268 \pm$ $467 \mathrm{~g}$ and $3250 \pm 485 \mathrm{~g}$, respectively, and the MPEs were $-3.3 \pm 6.6$ and $-3.9 \pm 6.1$, respectively. For the 3D TVol model, the proportion of fetuses with estimated error $\leq 5 \%$ was significantly higher than that of the $2 \mathrm{D}$ model $(55.4 \%$ vs. $33.9 \%, p<0.05)$. For fetuses with a birth weight $<3500 \mathrm{~g}$, the accuracy of the AVol and TVol models were better than the $2 \mathrm{D}$ model $(-0.8$ vs. 7.0 and -2.8 vs. 7.0, both $p<0.05)$. Moreover, for these fetuses, the proportions (Continued on next page)
\end{abstract}

\footnotetext{
*Correspondence: menghua_pumch@163.com; oy81@163.com

†Hua Meng and Yunshu Ouyang contributed equally to this work.

Department of ultrasound, Peking Union Medical College Hospital, Chinese Academy of Medical Sciences and Peking Union Medical College, Beijing 100730, China
}

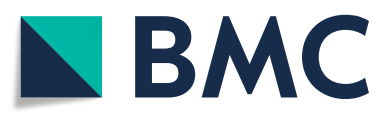

(c) The Author(s). 2021 Open Access This article is licensed under a Creative Commons Attribution 4.0 International License, which permits use, sharing, adaptation, distribution and reproduction in any medium or format, as long as you give appropriate credit to the original author(s) and the source, provide a link to the Creative Commons licence, and indicate if changes were made. The images or other third party material in this article are included in the article's Creative Commons licence, unless indicated otherwise in a credit line to the material. If material is not included in the article's Creative Commons licence and your intended use is not permitted by statutory regulation or exceeds the permitted use, you will need to obtain permission directly from the copyright holder. To view a copy of this licence, visit http://creativecommons.org/licenses/by/4.0/ The Creative Commons Public Domain Dedication waiver (http://creativecommons.org/publicdomain/zero/1.0/) applies to the data made available in this article, unless otherwise stated in a credit line to the data. 


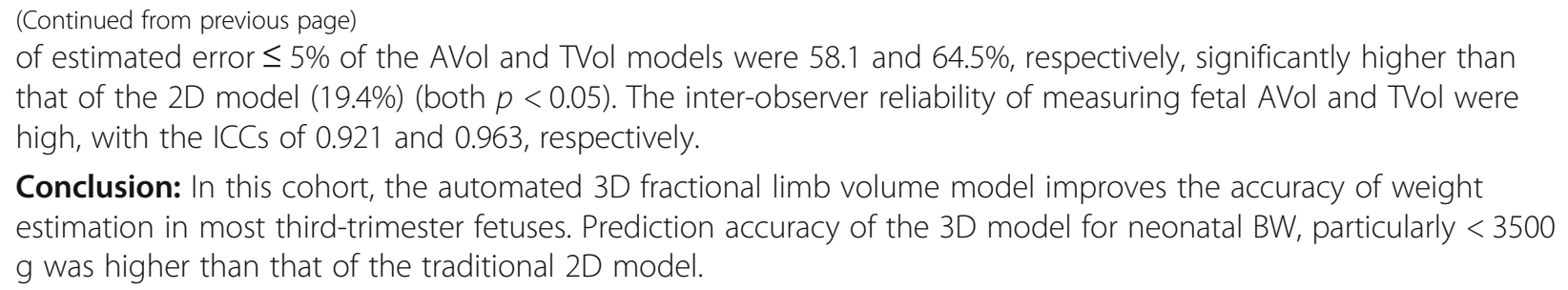

Conclusion: In this cohort, the automated 3D fractional limb volume model improves the accuracy of weight estimation in most third-trimester fetuses. Prediction accuracy of the 3D model for neonatal BW, particularly $<3500$ $\mathrm{g}$ was higher than that of the traditional 2D model.

Keywords: Ultrasound, Estimated fetal weight, Fractional arm volume, Fractional thigh volume, Three-dimensional ultrasound

\section{Background}

The birth weight $(\mathrm{BW})$ of newborns is intimately related to the maternal and perinatal prognosis. When the BW is too low or too high, morbidity and mortality are significantly higher than those of normal newborns. Fetal growth retardation (FGR) leads to low birth weight $(\mathrm{BW}<2500 \mathrm{~g})$ and increases the rate of cesarean section and risk of neurological complications and stillbirth [14]. Fetal oversize is associated with prolonged labor and various birth injuries, including shoulder dystocia, brachial plexus injury, and perinatal asphyxia, as well as increased maternal risks, such as obstetric laceration and postpartum hemorrhage [5-7].

In the third trimester, ultrasound measurement of fetal head, abdominal circumference, femoral length and other parameters to estimate fetal weight not only reflects fetal intrauterine nutrition, but also is an important aspect of prenatal care. Hadlock et al. [8] established a fetal weight estimation model using two-dimensional (2D) indexes of fetal head, abdominal circumference, and femur length. With the development of threedimensional (3D) ultrasound technology, limb volumes have gradually been incorporated into fetal weight estimation models [9-12]. Lee et al. [10] proposed the concept of fractional limb volume, which was added to the new weight prediction models as a fetal soft tissue parameter.

Previous studies have shown that fractional limb volume combined with other 2D biological indicators can improve the precision of fetal weight estimation [11-15]. However, due to the differences in sample size, gestational weeks of ultrasound examination, and ethnicity, the conclusions of different studies vary, and there are relatively few studies on the predictive ability of $3 \mathrm{D}$ models for newborns with different birth weights. A commercially available software tool (5D Limb Vol) launched in 2016 can automatically measure the fractional limb volume of the fetus approximately five times faster than manual tracing [16]. Therefore, the main objective of this study was to perform prospective validation regarding accuracy and precision of fetal weight estimation of Chinese fetuses in the third trimester using an automated 3D fractional limb volume model, and to compare this model with the traditional 2D model to determine its clinical application value.

\section{Methods \\ Study population}

A cross-sectional prospective observational study was conducted at the Department of Ultrasound in Peking Union Medical College Hospital from January 2018 to July 2019. All patients were identified during their routine clinical care in the prenatal clinic and then invited to participate in a separate research visit.

The inclusion criteria included single live birth, gestational age was calculated according to the last menstrual period and confirmed by ultrasound during the first trimester, and the pregnant women delivered after 34 weeks and delivery date was within 7 days of the last prenatal ultrasound examination. The exclusion criteria were (1) multifetal pregnancy; (2) unclear gestational age; (3) fetal chromosomal abnormality and/or structural malformation; (4) delivery date more than 7 days after the last ultrasound examination.

This study was approved by the Ethics Committee of Peking Union Medical College Hospital, Chinese Academy of Medical Sciences (HS-1420). Before the study was performed, we gave a detailed explanation to the pregnant women and provided written informed consents, and all informed consents were signed by the participants. Neonatal follow-up data included date of delivery, gestational age at delivery, birth weight, and sex.

\section{Ultrasonographic data acquisition}

All 2D biological parameters, including fetal biparietal diameter (BPD), abdominal circumference (AC), femur length (FL), and $3 \mathrm{D}$ volume data were acquired using a WS80A ultrasound system (Samsung Medison, Seoul, Korea) by a registered sonographer (XW), who had more than 5 years of experience with 3D ultrasonography. 3D ultrasound scans were performed using a convex volume probe (CV1-8A) to obtain the volume data sets of fetal arm and fetal thigh. 
The instrument parameters and processes were set according to previous research regulations $[14,16]$. The limbs closest to the anterior uterus wall were selected to display the maximum longitudinal section of the upper limb or lower limb long bone to initiate 3D ultrasound. For each pregnancy, two sonographic volume data sets of the fetal arm and fetal thigh were obtained. The scanning angle was set to $65^{\circ}-80^{\circ}$ according to different gestational ages with the high quality. When the fetus was large, a wide scan was select to ensure that the sampling frame contained the entire long bone volume of the upper or lower limb.

\section{Three-dimensional volume data analysis}

The best quality imaging were selected for analysis. The optimal imaging refers to no fetal movement artifacts and clear recognition of the soft tissue boundary.

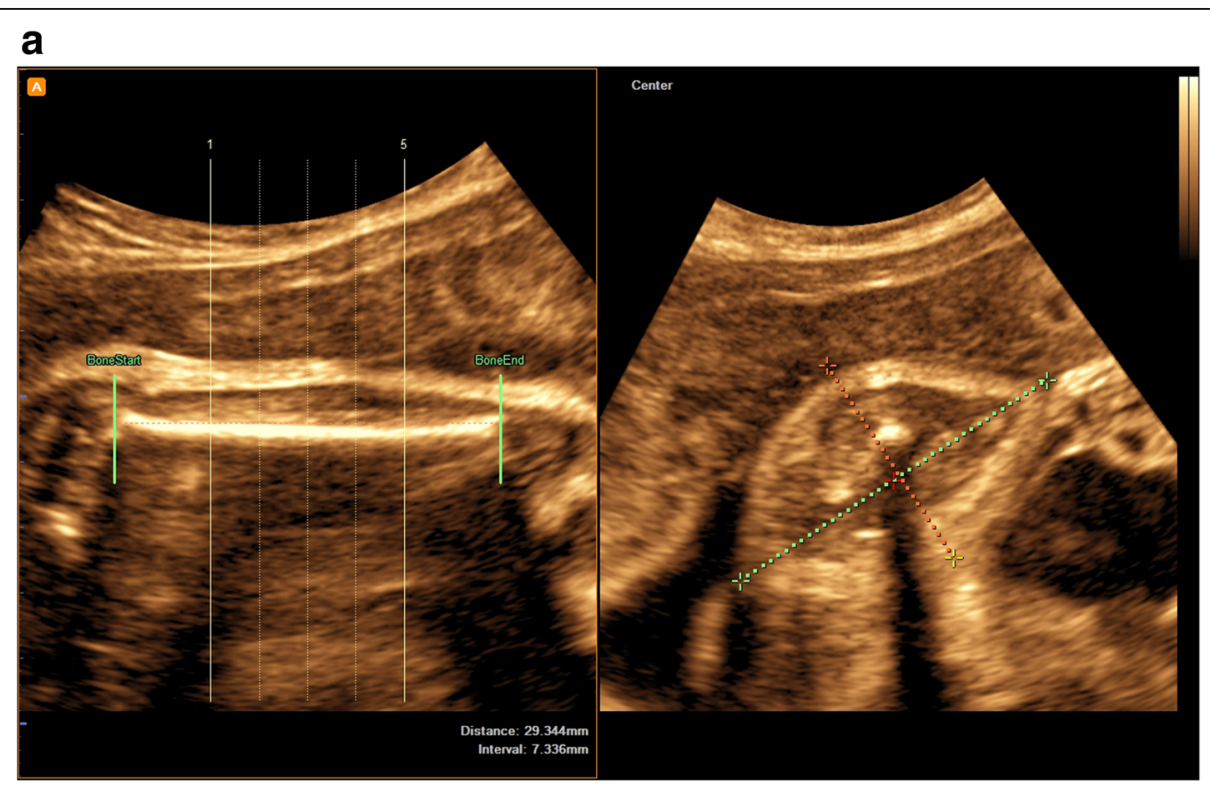

b

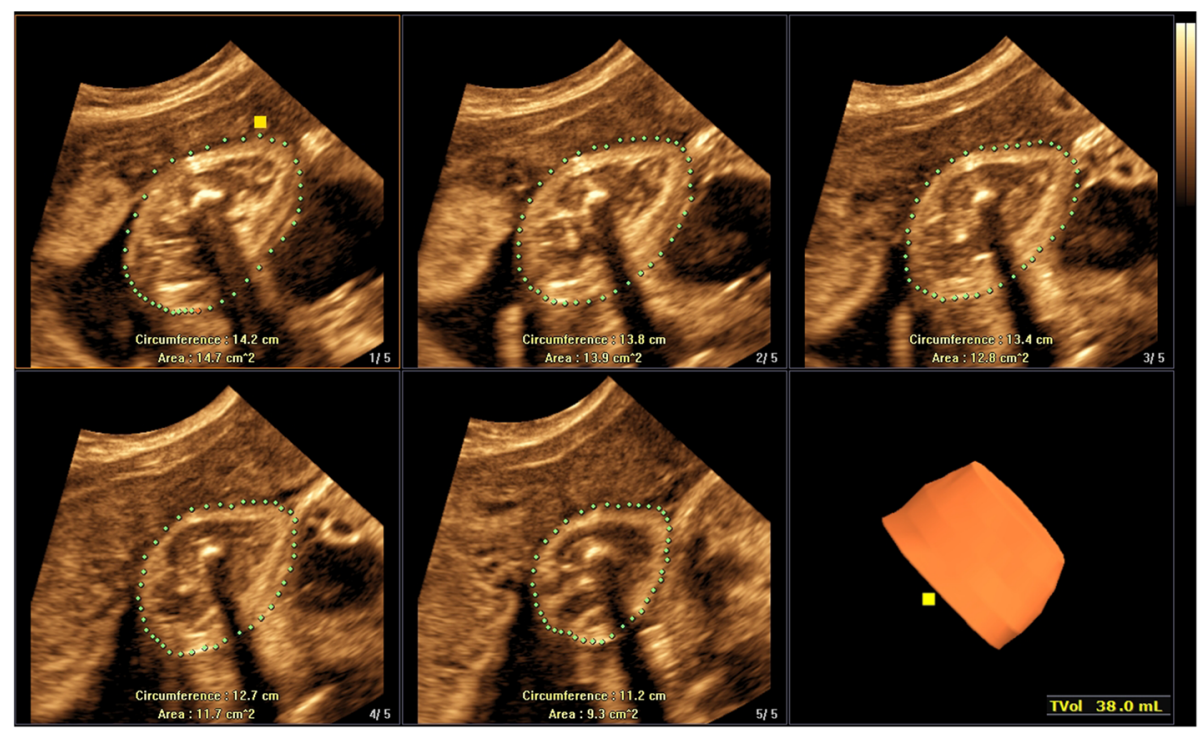

Fig. 1 Fractional thigh volume measurement was calculated by novel software (5D Limb Vol; Samsung Medison). a step 1. The software identifies both ends of thigh limb automatically. Limb soft tissue borders are manually marked by examiner for short and long-axis diameters (red and green dotted lines) to initiate a computer-assisted edge detection algorithm. $\mathbf{b}$ step 2 . The resulting fractional limb volume is divided into five subsections of equal length to allow automated tracing of surface contours from an axial view. The thigh volume and estimated fetal weight based BPD, AC and TVol were calculated automatically. BPD, biparietal diameter; AC, abdominal circumference; TVol, fractional thigh volume 
Analysis was performed using the 5D Limb Vol software of the WS80A ultrasound system (5D Limb Vol; Samsung Medison). In the first step, the multiplanar mode simultaneously displayed the sagittal section of the long bone and the cross section of the corresponding limb center. The software automatically marked the positions of the long bone ends, and the examiner manually labeled the major and minor axis diameters on the generated cross section. In the second step, according to the determined long bone ends of the limbs, the system divided the middle 50\% volume of the upper arm or the thigh of the fetus equally into five cross-sections and initiated the computer-assisted edge detection algorithm to automatically envelop the edges of the five limb crosssections. Minor adjustments were possible after visual inspection of automated results. Finally, the fractional limb volume was automatically obtained (Fig. 1).

The fetal fractional limbs volume measurements were repeated by another examiner (ZN), who had only 1 year of obstetric ultrasound experience. The examiner was blinded to all previous measurements calculated.

\section{Fetal weight estimation}

EFW was calculated by traditional 2D model using Hadlock's formula [8] which included measurements of BPD, $\mathrm{AC}$ and FL. Hadlock formula: $\log 10$ weight $=1.335-$ $0.0034 \mathrm{AC} x \mathrm{FL}+0.0316 \mathrm{BPD}+0.0457 \mathrm{AC}+0.1623 \mathrm{FL}$.

3D fractional limb volume model used the Lee formulas [11] to estimate the fetal weight, using fractional arm volume $(\mathrm{AVol})$ and fractional thigh volume (TVol) as parameters respectively.

Lee formulas: $\ln$ weight $=0.5046+1.9665$ (ln BPD) $0.3040 \quad(\ln \quad \mathrm{BPD})^{2}+0.9675 \ln \quad \mathrm{AC}+0.3557 \ln \quad \mathrm{AVol}$; $\ln$ weight $=-0.8297+4.0344(\ln \mathrm{BPD})-0.7820(\ln \mathrm{BPD})^{2}+$ $0.7853(\ln \mathrm{AC})+0.0528(\ln \mathrm{TVol})^{2}$. Ln function in the formulas stands for the natural logarithm.

\section{Statistical analysis}

We used the traditional 2D model and 3D fractional limb volume model to estimate fetal weight and calculated the systematic error and random error to evaluate the predictive performance of each model.

Accuracy, namely, the systematic error, is the mean percentage error (MPE) of the actual birth weight and estimated fetal weight, percentage error was defined as (estimated fetal weight - actual birth weight) divided by actual birth weight and multiplied by 100 . Precision, namely, the random error, is expressed by the standard deviation (SD) of the percentage error. Count data are expressed as the mean \pm SD. Differences between the models were compared using the Paired $t$ test. The frequency data were analyzed using the Chi-square test. A two-way random effects model with absolute agreement was used to calculate the intraclass correlation coefficient (ICC) to indicate the measurement consistency between different examiners. The average score was been chosen as the ICC value. An ICC $>0.7$ is commonly used to indicate sufficient reliability. To visually assess the systematic bias of different weight estimation models, we graphed scatter plots to describe the relationship of the difference between the estimated fetal weight and actual birth weight with the actual birth weight. Statistical analysis was performed using SPSS version 22.0 (IBM, Armonk, NY, USA). A two-sided $p$-value $<0.05$ was considered statistically significant.

\section{Results}

\section{Patient characteristics}

A total of 56 pregnant women with a single fetus were examined by ultrasound within 7 days before delivery (mean $1.1 \pm 1.9$ days). Demographic and clinical data are shown in Table 1. Pregnancy complications included 6 cases of gestational hypertension, 10 cases of gestational diabetes, and 4 cases of immune system diseases (systemic lupus erythematosus and Sjögren's syndrome).

\section{Comparison of 2D and 3D models}

The average fetal weight estimated by the 2D Hadlock model was $3478 \pm 467 \mathrm{~g}$, and the MPE with the actual birth weight was $3.2 \pm 8.9$. The average fetal weight

Table 1 Demographic and clinical details of the study participants $(n=56)$

\begin{tabular}{ll}
\hline Characteristics & Value \\
\hline Maternal age (years) & $31.7 \pm 3.5$ \\
Maternal BMI (Kg/m ${ }^{2}$ ) & $27.3 \pm 3.5$ \\
GA at diagnosis (weeks) & $39.6 \pm 1.4$ \\
Ultrasound to delivery interval (days) & $1.1 \pm 1.9$ \\
Birth weight (g) & $3393 \pm 530$ \\
Birthweight category (g) & \\
$<3500 \mathrm{~g}$ & 31 \\
$\geq 3500 \mathrm{~g}$ & 25 \\
Gravida & 23 \\
1 & 20 \\
2 & 12 \\
3 & 1 \\
4 & 38 \\
Mode of delivery & 18 \\
Vaginal delivery & \\
Cesarean section & 28 \\
Sex of the neonate & \\
Male & \\
Female &
\end{tabular}

GA gestational age, $B M I$ body mass index 
estimated by the 3D model using the AVol and TVol indicators were $3268 \pm 467 \mathrm{~g}$ and $3250 \pm 485 \mathrm{~g}$, respectively, and the MPEs were $-3.3 \pm 6.6$ and $-3.9 \pm 6.1$, respectively. The $2 \mathrm{D}$ model tends to overestimate, and the 3D models tend to underestimate. The two models have similar absolute differences between the estimated fetal weight and actual birth weight (both $<4 \%$ ), while the 3D models demonstrate better precision (lower random error, 6.6 vs. 8.9 and 6.1 vs. 8.9).

Figure 2 shows the scatter plots of the actual birth weight and the difference between the estimated fetal weight and the actual body weight for the three models: Hadlock, AVol, and TVol. The plots clearly reveal that the differences from the actual birth weight for the AVol and TVol models show a narrower distribution around zero than Hadlock model. The difference between estimated fetal weight and actual birth weight shows a negative slope for all three models, suggesting that these models tend to underestimate the birth weight of large fetuses and overestimate the birth weight of small fetuses.

The numbers of estimated error $\leq 5 \%$ of actual birth weight in the Hadlock model, AVol mode, and TVol model were 19,28 , and 31 , respectively, and the proportions were $33.9,50.0$, and $55.4 \%$, respectively. In the comparison of the proportion of estimated error $\leq 5 \%$, the TVol model was superior to the Hadlock model $(p<$ $0.05)$, and there was no statistical difference between the Hadlock and AVol models $(p=0.085)$. The proportions of estimated error $\leq 10 \%$ in the Hadlock model, AVol model, and TVol model were $75.0,82.1$, and $82.1 \%$, respectively, and there was no significant difference between the Hadlock model and the AVol model or TVol model (both $p=0.357$ ) (Table 2).

\section{Subgroup analysis}

The prediction power of the three models for different and extreme birth weight neonates was compared by subgroup analysis (Table 3 ).

The MPEs of the AVol and TVol model for newborns (31 cases) with $\mathrm{BW}<3500 \mathrm{~g}$ were $-0.8 \pm 6.9$ and $-2.8 \pm$ 5.9 , respectively, with significantly higher accuracy than that of the Hadlock model $(7.0 \pm 7.8)$ (both $p<0.05)$. The MPE of the Hadlock model for newborns (25 cases) with $\mathrm{BW} \geq 3500 \mathrm{~g}$ was $-1.5 \pm 8.1$, indicating better accuracy than the AVol model and TVol model $(-6.4 \pm$ $4.9,-5.2 \pm 6.0$ ) (both $p<0.05$ ). For newborns with BW < $3500 \mathrm{~g}$, the proportions with estimated error $\leq 5 \%$ were 19.4, 58.1, and $64.5 \%$ in the Hadlock model, the AVol model, and the TVol model, respectively. Both AVol and TVol models were significantly superior to the Hadlock model (both $p<0.05$ ). There was no significant difference in the proportion of estimated error $\leq 10 \%$ between the Hadlock model with the AVol and TVol models

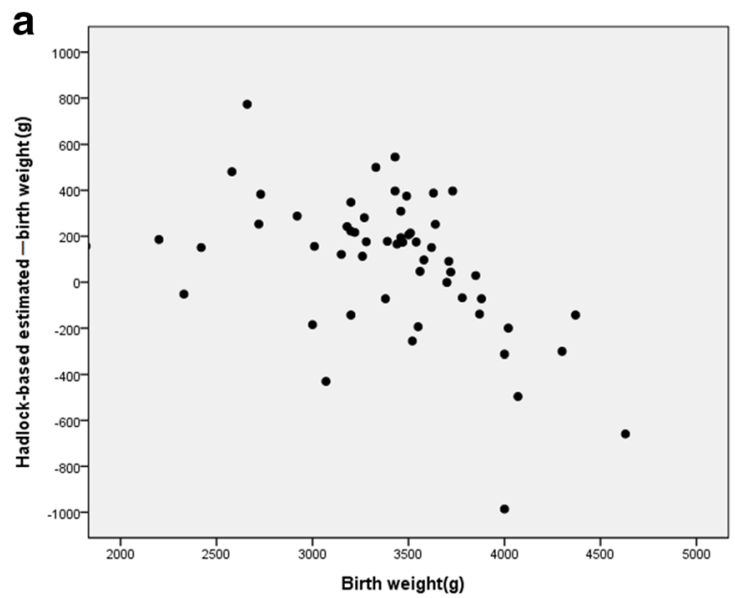

b

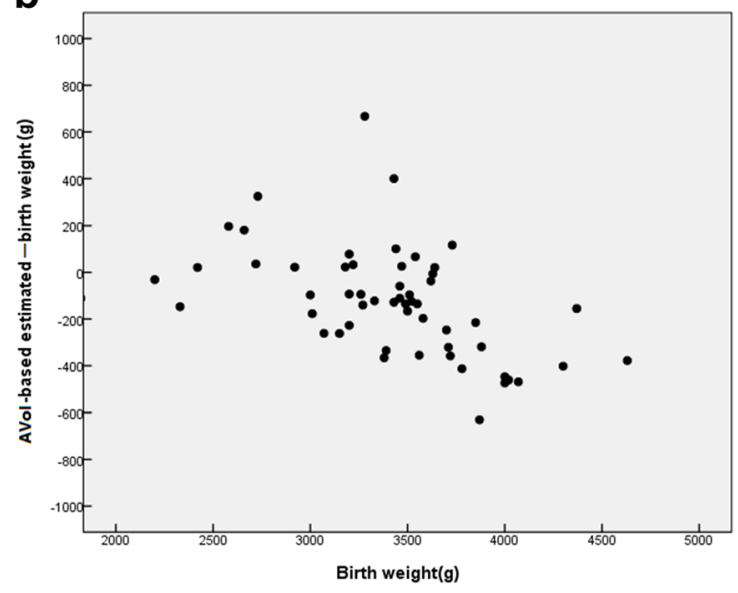

C

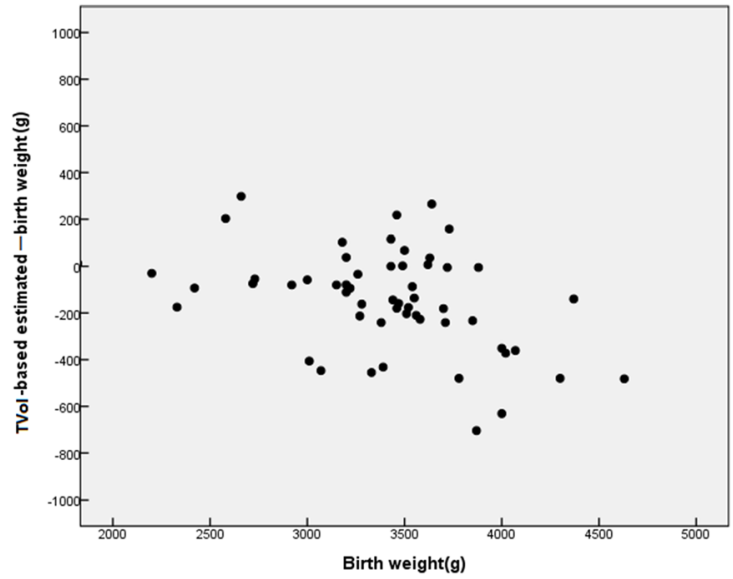

Fig. 2 Scatter plots of differences between three models estimated fetal weight and actual birth weight, in relation to actual birth weight. a: Hadlock model; b: AVol model; c: TVol model. AVol, fractional arm volume; TVol, fractional thigh volume

( $p=0.119, p=0.224$, respectively). For $\mathrm{BW} \geq 3500 \mathrm{~g}$, no statistical difference in the proportion of estimated errors $\leq 5 \%$ can be seen between the $2 \mathrm{D}$ model and the $3 \mathrm{D}$ model (Hadlock vs. AVol, $p=0.395$; Hadlock vs. TVol, 
Table 2 Comparison of two-dimensional and three-dimensional sonographic findings $(n=56)$

\begin{tabular}{llll}
\hline Sonographic Findings & Hadlock & AVol & TVol \\
\hline EFW (g) & $3478 \pm 467$ & $3268 \pm 467$ & $3250 \pm 485$ \\
MPE (\%) & $3.2 \pm 8.9$ & $-3.3 \pm 6.6$ & $-3.9 \pm 6.1$ \\
EFW within 5\% of BW, n (\%) & $19(33.9)$ & $28(50.0)$ & $31(55.4)$ \\
EFW within 10\% of BW, n (\%) & $42(75.0)$ & $46(82.1)$ & $46(82.1)$ \\
\hline
\end{tabular}

EFW estimated fetal weight, $B W$ birth weight, MPE mean percentage error, $A V o l$ fractional arm volume, $T V$ ol fractional thigh volume

Hadlock formula: $\log 10$ weight $=1.335-0.0034 \mathrm{AC} \times \mathrm{FL}+0.0316 \mathrm{BPD}+0.0457$ $A C+0.1623$ FL. Lee formulas: In weight $=0.5046+1.9665(\ln B P D)-0.3040(\ln$ $\mathrm{BPD})^{2}+0.9675 \ln \mathrm{AC}+0.3557$ In AVol; ln weight $=-0.8297+4.0344($ In BPD) $0.7820(\operatorname{ln~BPD})^{2}+0.7853(\ln \mathrm{AC})+0.0528(\ln \mathrm{TVol})^{2}$

$p=0.571)$, and the difference in the proportion of estimated error $\leq 10 \%$ between two types of models was not significant either (Hadlock vs. AVol, $p=0.733$; Hadlock vs. TVol, $p=1.000)$.

Four low-birth-weight newborns (BW $\leq 2500 \mathrm{~g})$ were clinically diagnosed as late-onset FGR, with an average birth weight of $2193 \mathrm{~g}$. The MPEs of the AVol and TVol models for estimating the FGR fetuses were $-3.2 \pm 3.5$ and $-3.0 \pm 3.5$, respectively, with higher accuracy than the Hadlock model $(5.3 \pm 5.1)$ (both $p<0.05)$. Seven macrosomic infants $(B W \geq 4000 \mathrm{~g})$ had an average birth weight of $4199 \mathrm{~g}$. With regard to the estimated weight of macrosomia, there was no statistical difference between the Hadlock model with the AVol and TVol models $(p=0.741, p=0.763$, respectively).

Table 3 Comparison of three antenatal ultrasonography models to predict different birth weight infants

\begin{tabular}{llll}
\hline Birth weight category & Hadlock & AVol & TVol \\
\hline BW $<3500 \mathrm{~g}, n=31$ & & & \\
MPE (\%) & $7.0 \pm 7.8$ & $-0.8 \pm 6.9$ & $-2.8 \pm 5.9$ \\
EFW within 5\% of BW, $\mathrm{n}(\%)$ & $6(19.4)$ & $18(58.1)$ & $20(64.5)$ \\
EFW within 10\% of BW, $\mathrm{n}(\%)$ & $22(71.0)$ & $27(87.1)$ & $26(83.9)$ \\
BW $\geq 3500 \mathrm{~g}, n=25$ & & & \\
MPE (\%) & $-1.5 \pm 8.1$ & $-6.4 \pm 4.9$ & $-5.2 \pm 6.0$ \\
EFW within 5\% of BW, $\mathrm{n}(\%)$ & $13(52.0)$ & $10(40.0)$ & $11(44.0)$ \\
EFW within 10\% of BW, $\mathrm{n}(\%)$ & $20(80.0)$ & $19(76.0)$ & $20(80.0)$ \\
BW $\leq 2500 \mathrm{~g}, n=4$ & & & \\
MPE (\%) & $5.3 \pm 5.1$ & $-3.2 \pm 3.5$ & $-3.0 \pm 3.5$ \\
BW $\geq 4000 \mathrm{~g}, n=7$ & & & \\
MPE (\%) & $-10.6 \pm 7.3$ & $-9.6 \pm 3.0$ & $-9.6 \pm 3.7$ \\
\hline
\end{tabular}

EFW estimated fetal weight, $B W$ birth weight, MPE mean percentage error, $A V o l$ fractional arm volume, $T V$ ol fractional thigh volume

Hadlock formula: $\log 10$ weight $=1.335-0.0034 \mathrm{AC} \times \mathrm{FL}+0.0316 \mathrm{BPD}+0.0457$ $\mathrm{AC}+0.1623 \mathrm{FL}$. Lee formulas: In weight $=0.5046+1.9665(\operatorname{In~BPD})-0.3040(\mathrm{In}$ $\mathrm{BPD})^{2}+0.9675 \ln \mathrm{AC}+0.3557 \ln$ AVol; In weight $=-0.8297+4.0344(\ln \mathrm{BPD})-$ $0.7820(\ln \mathrm{BPD})^{2}+0.7853(\ln \mathrm{AC})+0.0528(\ln \mathrm{TVol})^{2}$

\section{Inter-observer reliability}

The inter-observer reliability of measuring the fetal limb volumes using the 5D Limb Vol software tool were high. The ICC of AVol was 0.921 (95\% CI, 0.868-0.953), and the ICC of TVol was 0.963 (95\% CI, 0.937-0.978).

\section{Discussion}

Our study applied the 5D limb Vol software to the Chinese population alone. The results showed that there was no statistical difference in the accuracy of fetal weight estimation between the 3D fractional limb volume models and the traditional Hadlock 2D model, while the 3D models had low random error and higher precision. In the population of this study, using the AVol model and the TVol model, the differences between the estimated weight and actual birth weight of $\leq 5 \%$ were achieved for half of the fetuses, with proportions of 50.0 and $55.4 \%$, respectively, which were similar to the previous study results $[11,13]$ and significantly superior to the 2D Hadlock model (33.9\%).

Precise fetal weight estimation means that repeatable results are provided, which is extremely important for daily obstetric care. A review of the medical literature indicates that fractional limb volume has been used for EFW in many countries. Although the models used and sample size are different, many studies also have shown that the introduction of fractional limb volume improve the weight estimation precision of normal fetuses in the third trimester, which are similar to our research conclusions (Table 4). Therefore, 3D fractional limb volume model to estimate fetal weight may better meet the clinical requirements for the accuracy of fetal weight prediction.

The subgroup analysis of birth weight showed that the AVol and TVol models had high accuracy for the weight estimation of newborns $<3500 \mathrm{~g}$ in weight, and the proportions with an estimated weight difference of $\leq 5 \%$ were 58.1 and $64.5 \%$, respectively, significantly higher than that of the Hadlock model. In clinical practice, neonatal birth weight often does not exceed $3500 \mathrm{~g}$. Therefore, it can be speculated that acquisition of high-quality limb volumes with 3D sonography for fetal weight estimation can be feasible in these nonmacrosomic fetuses.

There were four newborns with $\mathrm{BW} \leq 2500 \mathrm{~g}$ in our group. Applying AVol and TVol models to estimate fetal weight before delivery had high accuracy, and the differences with birth weight were less than $5 \%$. All of the low-birth-weight newborns in this study were diagnosed late-onset FGR and were timely delivered at 34 to 38 weeks after indicating low weight by the 3D models. Accurate estimation of fetal weight by prenatal ultrasound is an important aspect of the identification and diagnosis of FGR; however, the detection rate of late-onset FGR is only 23 to $51 \%$ [17, 18]. Simcox et al. also showed that using the TVol to estimate fetal weight increased the 
Table 4 Summary of fetal weight estimation studies based on fractional limb volume

\begin{tabular}{|c|c|c|c|c|c|c|c|}
\hline First author & Sample size & $\begin{array}{l}\text { Gestational } \\
\text { age (weeks) }\end{array}$ & $\begin{array}{l}\text { Birth } \\
\text { weight (g) }\end{array}$ & Main comments & MPE (\%) & $\begin{array}{l}\text { EFW within } \\
5 \% \text { of BW (\%) }\end{array}$ & $\begin{array}{l}\text { EFW within } \\
10 \% \text { of BW (\%) }\end{array}$ \\
\hline Lee (2001) [10] & $\begin{array}{l}100 \text { for model } \\
\text { derivation,30 } \\
\text { for validation }\end{array}$ & $39.2 \pm 1.2$ & $3643 \pm 574$ & $\begin{array}{l}\text { The model containing AC and } \\
\text { TVol had the best predictive } \\
\text { capacity for fetal weight. }\end{array}$ & $2.3 \pm 6.6$ & 66.67 & 96.67 \\
\hline Lee (2009) [11] & 271 & $\begin{array}{l}\text { scanned within } \\
4 \text { days of } \\
\text { delivery }\end{array}$ & $235-5790$ & $\begin{array}{l}\text { Two models, which used the } \\
\text { natural logarithms of BPD, AC, } \\
\text { AVol and TVol provided the } \\
\text { most precise weight estimations. }\end{array}$ & $\begin{array}{l}0.18 \pm \\
6.6(\mathrm{AVol}) \\
0.12 \pm 6.6(\mathrm{TVOl})\end{array}$ & $\begin{array}{l}\text { 50.4(AVol) } \\
57.3(\mathrm{TVOl})\end{array}$ & $\begin{array}{l}\text { 89.8(AVol) } \\
\text { 84.1(TVol) }\end{array}$ \\
\hline Yang (2011) [12] & $\begin{array}{l}100 \text { for model } \\
\text { derivation,190 } \\
\text { for validation }\end{array}$ & $38.7 \pm 3.1$ & $3202 \pm 360$ & $\begin{array}{l}\text { The prediction model using } \\
\text { TVol, FL, AC and BPD provided } \\
\text { the most precise birth-weight } \\
\text { estimation. }\end{array}$ & $0.23 \pm 4.68$ & 69.5 & 95.3 \\
\hline Lee (2013) [13] & 164 & $37.1 \pm 4.1$ & $\begin{array}{l}3057 \pm \\
1102\end{array}$ & $\begin{array}{l}\text { Optimal model performance } \\
\text { resulted from using a } \\
\text { combination of BPD, AC and } \\
\text { TVol. }\end{array}$ & $1.9 \pm 6.6$ & 55.1 & 86.5 \\
\hline $\operatorname{Mack(2017)~[14]~}$ & 50 & $39.1 \pm 1.4$ & 3335 & $\begin{array}{l}\text { Automated fractional limb } \\
\text { volume measurements } \\
\text { improved the precision of } \\
\text { weight predictions in third- } \\
\text { trimester fetuses. }\end{array}$ & $\begin{array}{l}-9.1 \pm \\
5.1(\mathrm{AVol}) \\
-5.2 \pm \\
5.2(\mathrm{TVOl})\end{array}$ & Not provided & \\
\hline $\begin{array}{l}\text { Sharma(2019) } \\
{[15]}\end{array}$ & $\begin{array}{l}100 \text { for model } \\
\text { derivation,31 } \\
\text { for validation }\end{array}$ & $38.0 \pm 0.9$ & $3039.2 \pm 42$ & $\begin{array}{l}\text { The best fit model for fetal } \\
\text { weight estimation comprised } \\
B P D, H C, A C \text {, and TVol. }\end{array}$ & $0.624 \pm 8.075$ & 70.2 & 91.6 \\
\hline Wu (current) & 56 & $39.6 \pm 1.4$ & $3393 \pm 530$ & $\begin{array}{l}\text { Automated 3D fractional limb } \\
\text { volume model improved the } \\
\text { accuracy of weight estimation } \\
\text { in most third-trimester fetuses. }\end{array}$ & $\begin{array}{l}-3.3 \pm \\
6.6(\mathrm{AVol}) \\
-3.9 \pm \\
6.1(\mathrm{TVOl})\end{array}$ & $\begin{array}{l}\text { 50.0(AVol) } \\
\text { 55.4(AVol) }\end{array}$ & $\begin{array}{l}\text { 82.1 (both of } \\
\text { AVol and TVol) }\end{array}$ \\
\hline
\end{tabular}

EFW estimated fetal weight, BW birth weight, MPE mean percentage error, AVol fractional arm volume, TVol fractional thigh volume

detection rate of 34- to 36-week late-onset FGR [19]. Therefore, our results indicate that the application of 3D fractional limb volume model to estimate fetal weight may help detect fetal growth and development abnormalities in time and improve the detection of lowweight fetuses or late-onset FGR.

Different opinions have been offered on the weight estimation of macrosomia [20-23]. Gibson et al. have shown that TVol is the optimum ultrasound index for predicting the weight of macrosomia [23]. A recent multicenter study also showed that there was a clear trend for automated fractional limb models to provide improved weight estimates in larger fetuses with BW of greater than $4000 \mathrm{~g}$ [24], while other studies have shown that the accuracy of different weight estimation models decreases with increasing fetal weight $[25,26]$. The data in our study showed that there was no significant difference in the accuracy of weight estimation between the $3 \mathrm{D}$ model and the 2D model for seven cases of macrosomia (BW $\geq 4000 \mathrm{~g})$. This study also showed that the estimation accuracy of the 3D model for newborns with $\mathrm{BW} \geq 3500 \mathrm{~g}$ was not as good as that for newborns with $\mathrm{BW}<3500 \mathrm{~g}$. The possible reason is that the soft tissue of the fetuses more than $3500 \mathrm{~g}$ of estimated weight could be compressed in the uterus, which affects the recognition of the limb boundary, thus limits the acquisition and analysis of the 3D volume data to some extent. Therefore, the accurate estimation of large fetuses using the $3 \mathrm{D}$ fractional limb volume requires the accumulation of further experience, and better indicators to quantify fetal soft tissue and developing new models to predict neonatal adiposity.

In most previous studies, the primary limitation of using 3D ultrasound to measure fetal limb volume was to manually trace the limb boundaries of the five crosssections $[10-13,15]$, which is time consuming and leads to limited clinical application. The 5D limb vol software in this study uses computer-aided measurement technology, which can automatically trace the boundary of the limb in cross-sections to obtain fetal limb volume and estimated fetal weight, and manual adjustment can be conducted if needed. The measurement time of a limb volume using this software is only about $30-40 \mathrm{~s}$, while it took about $2 \mathrm{~min}$ to obtain the limb volume by manually tracing the limb boundary. Moreover, the optimaluse of sonographic fetal biometry depends on an operator-dependent procedure that requires careful attention to the measurement protocol and the use of appropriate imaging equipment. Operators with inexperience are likely to cause large measurement errors. Our study analyzed the use of 5D limb vol software by examiners with different experience in obstetric 
ultrasound to evaluate the consistency of fetal $\mathrm{AVol}$ and TVol. The results showed that relatively good agreement of the AVol and TVol measurements between the novice and experienced operators, indicating that the use of automatic limb volume software to estimate fetal weight is conducive for reducing operator dependence. Automated fractional limb volume measurements is easy to operate and timesaving, and has broad clinical application prospects.

Small sample size is the main limitation of our research, especially the numbers of low-birth-weight newborns and macrosomia. The accuracy of estimating fetuses with extreme birth weights using fractional limb volume awaits further study. Additionally, there were no cases with extremely low volumes of amniotic fluid in the target population, and it is thereby impossible to determine the effect of amniotic fluid volume on the image quality of 3D limb volume.

\section{Conclusions}

In summary, this pilot study used automated limb volume estimation software to prospectively evaluate the weight of Chinese fetuses in the third trimester. Prediction accuracy of the 3D model for neonatal BW, particularly $<3500 \mathrm{~g}$ was higher than that of the traditional 2D model, suggesting potentially good clinical application prospects of the $3 \mathrm{D}$ model.

\section{Abbreviations}

2D: Two-dimensional; 3D: Three-dimensional; AVol: Fractional arm volume; TVol: Fractional thigh volume; BPD: Biparietal diameter; AC: Abdominal circumference; FL: Femur length; MPE: Mean percentage error; EFW: Estimated fetal weight; BW: Birth weight; FGR: Fetal growth retardation; ICC: Intraclass correlation coefficient; g: Grams

\section{Acknowledgements}

The authors thank Haiying Gong for her great help in data analysis.

\section{Authors' contributions}

$X W, H M$ and $Y O$ conceived and designed the experiments, XW and ZN performed the experiments and collected the data. XW, ZX, YJ and $Y Z$ performed the experiments and reviewed drafts of the paper. All authors were involved in writing the article and had approved final version of manuscript to be submitted.

\section{Funding}

This research was supported by grants from 2019 PUMCH Science Fund for Junior Faculty (pumch201911591).

\section{Availability of data and materials}

All data generated or analysed during this study are included in this published article (Results section and tables within the manuscript).

\section{Declarations}

\section{Ethics approval and consent to participate}

This study was approved by the Ethics Committee of Peking Union Medical College Hospital, Chinese Academy of Medical Sciences (HS-1420). All informed consents were signed by the participants. We declare that all methods of this research were performed in accordance with the relevant guidelines and regulations (Declaration of Helsinki).
Consent for publication

Not applicable.

\section{Competing interests}

The authors declare there are no competing interests.

Received: 23 February 2021 Accepted: 19 April 2021

Published online: 08 May 2021

\section{References}

1. Moraitis AA, Wood AM, Fleming M, Smith GCS. Birth weight percentile and the risk of term perinatal death. Obstet Gynecol. 2014;124(2, PART 1):274-83. https://doi.org/10.1097/AOG.0000000000000388.

2. Gardosi J, Madurasinghe V, Williams M, Malik A, Francis A. Maternal and fetal risk factors for stillbirth: population based study. BMJ. 2013;346(Clinical research ed.):f108. https://doi.org/10.1136/bmj.f108.

3. Trudell AS, Tuuli MG, Cahill AG, Macones GA, Odibo AO. Balancing the risks of stillbirth and neonatal death in the early preterm small-for-gestationalage fetus. Am J Obstet Gynecol. 2014;211(3):295.e1-295.e2957. https://doi. org/10.1016/j.ajog.2014.04.021.

4. Pilliod RA, Cheng YW, Snowden JM, Doss AE, Caughey AB. The risk of intrauterine fetal death in the small-for-gestational-age fetus. Am J Obstet Gynecol. 2012;207(4):318.e1-318.e3186. https://doi.org/10.1016/j.a jog.2012.06.039.

5. Haram K, Pirhonen J, Bergsjø P. Suspected big baby: a difficult clinical problem in obstetrics. Acta Obstet Gynecol Scand. 2002;81(3):185-94. https://doi.org/10.1034/j.1600-0412.2002.810301.x.

6. Siggelkow W, Boehm D, Skala C, Grosslercher M, Schmidt M, Koelbl H. The influence of macrosomia on the duration of labor, the mode of delivery and intrapartum complications. Arch Gynecol Obstet. 2008;278(6):547-53. https://doi.org/10.1007/s00404-008-0630-7.

7. Stotland NE, Caughey AB, Breed EM, Escobar GJ. Risk factors and obstetric complications associated with macrosomia. Int J Gynaecol Obstet. 2004; 87(3):220-6. https://doi.org/10.1016/j.ijgo.2004.08.010.

8. Hadlock F, Harris R, Sharman R, Deter R, Park C. Estimation of fetal weight with the use of head, body and femur measurement: a prospective study. Am J Obstet Gynecol. 1985;151(3):333-7. https://doi.org/10.1016/0002-93 78(85)90298-4.

9. Chang FM, Liang Rl, Ko HC, Yao BL, Yu CH. Three-dimensional ultrasoundassessed fetal thigh volumetry in predicting birth weight. Obstet Gynecol. 1997;90(3):331-9. https://doi.org/10.1016/s0029-7844(97)00280-9.

10. Lee W, Deter RL, Ebersole JD, Huang R, Blanckaert K, Romero R. Birth weight prediction by three-dimensional ultrasonography: fractional limb volume. J Ultrasound Med. 2001;20(12):1283-92. https://doi.org/10.7863/jum.2001.2 0.12 .1283 .

11. Lee W, Balasubramaniam M, Deter RL, Yeo L, Hassan SS, Gotsch F, et al. New fetal weight estimation models using fractional limb volume. Ultrasound Obstet Gynecol. 2009;34(5):556-65. https://doi.org/10.1002/uog.7327.

12. Yang F, Leung KY, Hou YW, Yuan Y, Tang HY. Birth-weight prediction using three-dimensional sonographic fractional thigh volume at term in a chinese population. Ultrasound Obstet Gynecol. 2011;38(4):425-33. https://doi.org/1 0.1002/uog. 8945.

13. Lee W, Deter R, Sangi-Haghpeykar H, Yeo L, Romero R. Prospective validation of fetal weight estimation using fractional limb volume. Ultrasound Obstet Gynecol. 2013;41(2):198-203. https://doi.org/10.1002/ uog. 11185 .

14. Mack LM, Kim SY, Lee S, Sangi-Haghpeykar H, Lee W. Automated fractional limb volume measurements improve the precision of birth weight predictions in late third-trimester fetuses. J Ultrasound Med. 2017:36(8): 1649-55. https://doi.org/10.7863/ultra.16.08087.

15. Sharma AK, Das D, Dadhwal V, Deka D, Singhal S, Vanamail P. Twodimensional fetal biometry versus three-dimensional fractional thigh volume for ultrasonographic prediction of birthweight. Int J Gynaecol Obstet. 2019;145(1):47-53. https://doi.org/10.1002/ijgo.12770.

16. Mack LM, Kim SY, Lee S, Sangi-Haghpeykar H, Lee W. A novel semiautomated fractional limb volume tool for rapid and reproducible fetal soft tissue assessment. J Ultrasound Med. 2016;35(7):1573-8. https://doi. org/10.7863/ultra.15.09086

17. Poon LC, Syngelaki A, Akolekar R, Lai J, Nicolaides KH. Combined screening for preeclampsia and small for gestational age at 11-13 weeks. Fetal Diagn Ther. 2013;33(1):16-27. https://doi.org/10.1159/000341712. 
18. Crovetto F, Crispi F, Scazzocchio E, Mercade I, Meler E, Figueras F, et al. Firsttrimester screening for early and late small-for-gestational-age neonates using maternal serum biochemistry, blood pressure and uterine artery doppler. Ultrasound Obstet Gynecol. 2014;43(1):34-40. https://doi.org/10.1 002/uog. 12537.

19. Simcox LE, Myers JE, Cole TJ, Johnstone ED. Fractional fetal thigh volume in the prediction of normal and abnormal fetal growth during the third trimester of pregnancy. Am J Obstet Gynecol. 2017;217(4):453.e1-453.e12. https://doi.org/10.1016/j.ajog.2017.06.018.

20. Pagani G, Palai N, Zatti S, Fratelli N, Prefumo F, Frusca T. Fetal weight estimation in gestational diabetic pregnancies: comparison between conventional and three-dimensional fractional thigh volume methods using gestation-adjusted projection. Ultrasound Obstet Gynecol. 2014;43(1):72-6. https://doi.org/10.1002/uog.12458.

21. Combs CA, Rosenn B, Miodovnik M, Siddiqi TA. Sonographic EFW and macrosomia: is there an optimum formula to predict diabetic fetal macrosomia? J Matern Fetal Med. 2000;9(1):55-61. https://doi.org/10.1002/ (SICI)1520-6661 (200001/02)9:1<55::AID-MFM12>3.0.CO;2-9.

22. Gibson KS, Stetzer B, Catalano PM, Myers SA. Comparison of 2- and 3dimensional sonography for estimation of birth weight and neonatal adiposity in the setting of suspected fetal macrosomia. J Ultrasound Med. 2016;35(6):1123-9. https://doi.org/10.7863/ultra.15.06106.

23. Tuuli MG, Kapalka K, Macones GA, Cahill AG. Three-versus two-dimensional sonographic biometry for predicting birth weight and macrosomia in diabetic pregnancies. J Ultrasound Med. 2016;35(9):1925-30. https://doi. org/10.7863/ultra.15.08032.

24. Lee W, Mack LM, Sangi-Haghpeykar H, Gandhi R, Wu Q, Kang L, et al. Fetal weight estimation using automated fractional limb volume with 2 dimensional size parameters: a multicenter study. J Ultrasound Med. 2020; 39(7):1317-24. https://doi.org/10.1002/jum.15224.

25. Ross MG, Kjos SL. Estimation of birth weight by two-dimensional ultrasonography. Obstet Gynecol. 2008;111(5):1215. https://doi.org/10.1 097/AOG.0b013e3181727000.

26. Hoopmann M, Abele H, Wagner N, Wallwiener D, Kagan KO. Performance of 36 different weight estimation formulae in fetuses with macrosomia. Fetal Diagn Ther. 2010;27(4):204-13. https://doi.org/10.1159/000299475.

\section{Publisher's Note}

Springer Nature remains neutral with regard to jurisdictional claims in published maps and institutional affiliations.

Ready to submit your research? Choose BMC and benefit from:

- fast, convenient online submission

- thorough peer review by experienced researchers in your field

- rapid publication on acceptance

- support for research data, including large and complex data types

- gold Open Access which fosters wider collaboration and increased citations

- maximum visibility for your research: over $100 \mathrm{M}$ website views per year

At $\mathrm{BMC}$, research is always in progress.

Learn more biomedcentral.com/submissions 